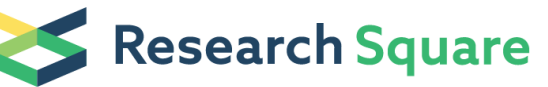

\section{Ibuprophen Removal from Synthetic Effluents Using Electrocoagulation-Peroxidation (ECP)}

\section{Laura Behling}

UFFS: Universidade Federal da Fronteira Sul

Vilson Conrado da Luz

UFFS: Universidade Federal da Fronteira Sul

Gean Delise Leal Pasquali ( $\sim$ geandelise@uffs.edu.br)

Universidade Federal da Fronteira Sul https://orcid.org/0000-0001-5110-6532

\section{Suzana Fátima Bazoti}

UFFS: Universidade Federal da Fronteira Sul

\section{Clarissa Dalla Rosa}

UFFS: Universidade Federal da Fronteira Sul

\section{Paulo Pereira}

UFFS: Universidade Federal da Fronteira Sul

\section{Research Article}

Keywords: Emerging contaminants, Scrap iron electrode, Hydrogen peroxide, High performance liquid chromatography, Electrochemical process, Medicines

Posted Date: June 24th, 2021

DOl: https://doi.org/10.21203/rs.3.rs-485175/v1

License: (c) (i) This work is licensed under a Creative Commons Attribution 4.0 International License.

Read Full License 
IBUPROPHEN REMOVAL FROM SYNTHETIC EFFLUENTS USING ELECTROCOAGULATION-

PEROXIDATION (ECP)

Laura Behling ${ }^{1}$, Vilson Conrado da Luz², Gean Delise Leal Pasquali ${ }^{\text {* }}$, Suzana Fátima Bazoti ${ }^{l}$, Clarissa

Dalla Rosa ${ }^{1}$, Paulo Pereira ${ }^{2}$

${ }^{1}$ Post-Graduation Program in Science and Environmental Technology, ${ }^{2}$ Environmental and Sanitary

Engineering Department - Federal University of Fronteira Sul, ERS 135 -Km 72, No 200, ZIP: 99700-970,

PO Box 764 - Erechim - RS - Brazil.

*Corresponding Author: Gean Delise Leal Pasquali (geandelise@uffs.edu.br) Phone No.: +55 (54) 3321-

\section{Declarations}

20 Ethics approval and consent to participate: Not applicable

21 Consent for publication: Not applicable

22 Availability of data and materials: All data generated or analysed during this study are included in this 23 published article [and its supplementary information files].

24 Competing interests: The authors declare that they have no competing interests

25 Funding: Federal University of Fronteira Sul (UFFS) was responsible for the laboratory area and the 26 acquisition of reagents and equipment, (scientific initiation scholarship ${ }^{\circ}{ }^{\circ} 270 /$ UFFS /2020)

27 Authors' contributions: All authors contributed to the study conception and design. Material preparation, data 28 collection and analysis were performed by Laura Behling, Vilson Conrado da Luz, Gean Delise Leal Pasquali 29 Vargas, Suzana Fátima Bazoti, Clarissa Dalla Rosa and Paulo Pereira. The first draft of the manuscript was

30 written by Laura Behling, Vilson Conrado da Luz and Gean Delise Leal Pasquali and all authors commented 31 on previous versions of the manuscript. All authors read and approved the final manuscript.

32 Acknowledgements: The authors gratefully acknowledge the Federal University of Fronteira Sul for the 33 financial support (grant $\left.n^{\circ} 270 / \mathrm{UFFS} / 2020\right)$ 
Abstract

36 Concerning water resources, several ordinances and legislation determine standards and conditions for the 37 discharge of effluents into water bodies. However, several contaminants are not covered by these guidelines

38 because they are found in low concentrations and due to little knowledge of their long-term effects. These 39 contaminants are called emergents, and this category includes drugs, such as anti-inflammatory drugs. The 40 electrocoagulation process associated with advanced oxidation comes up as an alternative to conventional 41 effluent treatment processes, and the objective of this work was to evaluate this process using scrap iron as 42 sacrificial electrodes in the treatment of synthetic effluents containing Ibuprofen. High performance liquid 43 chromatography (HPLC) was used to quantify the drug in synthetic effluents. The CCRD $2^{4}$ was used in an 44 experimental design, having as independent variables evaluated the concentration of contaminants, applied 45 current, the concentration of the primary oxidizing agent $\mathrm{H}_{2} \mathrm{O}_{2}$ and the reaction time. The optimized conditions 46 determined by statistical analysis were drug concentration of $5 \mathrm{mg} . \mathrm{L}^{-1}, \mathrm{H}_{2} \mathrm{O}_{2}$ concentration of $200 \mathrm{mg} . \mathrm{L}^{-1}$, 47 current of $5 \mathrm{~A}$ and $150 \mathrm{~min}$. The removals obtained under these conditions were higher than $92 \%$ in the 48 aqueous phase, showing that ECP technique has the potential to treat contaminants such as drugs present in 49 effluents and waters.

51 Keywords: Emerging contaminants. Scrap iron electrode. Hydrogen peroxide. High performance liquid 52 chromatography. Electrochemical process. Medicines.

\section{1. Introduction}

One of the main concerns of society today is the preservation of water resources, in view of the importance of water for the life of all species on the planet. Among the various contaminants studied that may affect this natural resource, the so-called emerging contaminants have stood out in the last decade.

Emerging contaminants are defined as a class of contaminants that has evolved as a result of the 60 development of new products, most of these are not inserted in monitoring programs or environmental legislation. Emerging contaminants are chemical substances (synthetic or natural) that were recently detected in the environment and there is little information about the environmental and public health risks that they may cause (Naidu et al. 2016). Among the emerging contaminants, which are produced on a large industrial scale, drugs stand out, as they are directly linked to human health (Ebele et al. 2016). Among the drugs most used by self-medication in Brazil, Ibuprofen stands out (Arrais et al. 2016). The continuous disposal of drugs in water bodies is a worldwide socio-environmental problem.

Chronic exposure to drugs can cause unexpected effects on the human organism and other living 68 beings (Torres 2012). That said, much research and discussion has been carried out regarding the presence of 69 drugs in water, underground and surface bodies. These compounds, when discarded improperly in the environment, are almost unchanged (Aramani and Readman 2007). This contamination is a major challenge for water distributors and public health. Some research has shown the consequences of emerging contaminants in the environment, such as hormonal damage in aquatic beings, impaired development of insects and invertebrates, inhibition of algae photosynthesis, in humans there is an increase in the incidence of breast, testicular and prostate cancer, infertility and endometriosis (Naidu et al. 2016; Machado et al. 2016). 
The concentration of these drugs in the effluent treatment stations can reach the level of $\mu \mathrm{g} . \mathrm{L}^{-1}$ and,

76 in some treatment stations, aimed at the treatment of drug effluents, it can reach levels of mg. $L^{-1}$ (Santos et al. 2009; Sim et al. 2011; Zhao et al. 2019).

Most of the water used for human supply in Brazil originates from surface water treatment, requiring advanced treatment to eliminate various pollutants. But most treatment plants use conventional processes, inefficient for emerging contaminants (Machado et al. 2016). Another source of contamination is the inappropriate disposal of drugs, which is of greater relevance in view of the growing consumption of medicines by the population, Figure 1 shows possible pharmaceuticals paths in the environment.

\section{3}

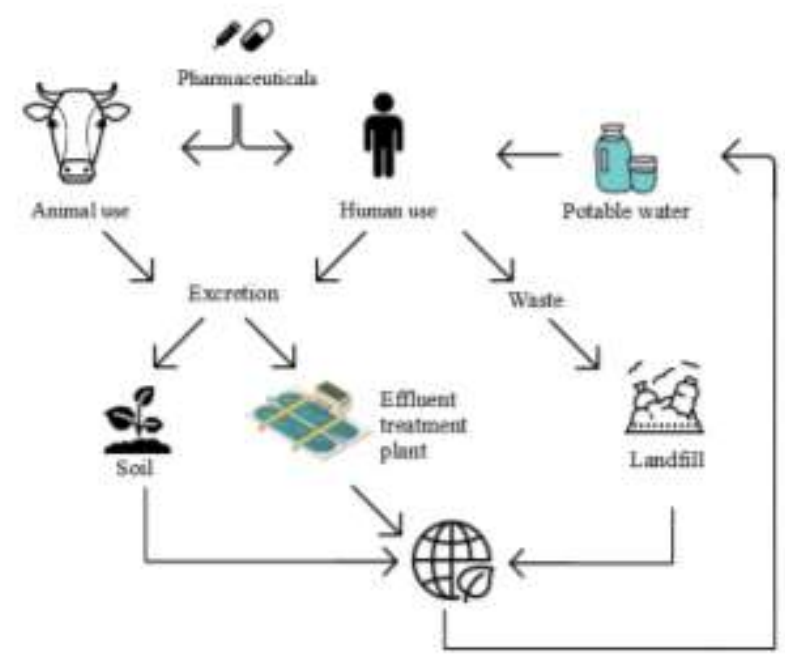

Fig. 1 Possible pharmaceuticals paths in the environment

In order to minimize environmental impacts, it is necessary to develop treatment technologies that combine low cost and high efficiency. In this context, the electrocoagulation (EC) process appears as an alternative to conventional effluent treatment processes, and it can be associated with the presence of a primary oxidizing agent, which may enhance the process of removing contaminants, as it associates the electrochemical process with advanced oxidative processes (AOPs), where the formation of hydroxyl radicals $(* \mathrm{OH})$ that present a high oxidative potential occurs, and in this way make the EC process more effective.

Several electrochemical methodologies are applied in wastewater treatment, including electrocoagulation, which was highlighted due to its advantages (Deghles and Kurt 2016). Electrocoagulation is an electrolytic process that consists of dissolving a sacrificial electrode after applying a current between two electrodes to treat liquid wastewater containing organic pollutants (Khemila et al. 2018).

According to Aquino Neto et al. (2012), the electrocoagulation process occurs in three stages. Initially, the cations that are generated in the oxidation of the sacrificial metal anode will react with the water molecules to form hydroxides and polyhydroxides. Iron and aluminum are the metallic materials most used as sacrificial electrodes, due to their low cost and high efficiency. At the same time, electrolysis of water occurs and the formation of oxygen and hydrogen microbubbles, which will later serve to load the flocculated material to the surface. Then, the hydroxides that have been formed are adsorbed into colloidal particles that will cause the formation of the floccules, which during their transport, end up in contact with the impurities. Flotation occurs due to the formation of microbubbles of oxygen at the anode and hydrogen at the cathode, due to water electrolysis. The pollutants end up being dragged to the surface, clarifying the effluent. 
The electrochemical reactions, of the metal as anode and cathode, can be summarized according to

106 Equations 1 to 6 (Mollah et al. 2004; Chen, 2004; Gabriel 2017):

107 For the iron anode:

Electrocoagulation has been widely used in the treatment of industrial effluents, such as effluent from the textile industry (Tones 2015), refrigerator (Eryuruk et al. 2018), tannery (Pavão et al. 2018), dairy (Behling et al. 2018), oily effluent (Cometti et al. 2014), paper and cellulose (Carvalho et al. 2015), biodiesel (Cordeiro et al. 2015), drugs (Olvera-Vargas et al. 2021) among other types. It is a particularly effective technique for a wide range of pollutants, such as heavy metals, organic compounds, microorganisms and several others, due to this, it is receiving greater prominence today.

One of the ways to potentiate the effect of electrocoagulation is the use of oxidizing agents such as hydrogen peroxide, since in addition to the removal by the formation of the coagulant, it can accentuate the eralization of the contaminants, and its decomposition generates *OH radicals, which present high oxidative potential and thus has the ability to degrade these compounds reaching mineralization.

Due to their remarkable mineralization efficiency and because they are considered ecologically correct, advanced electrochemical oxidation processes (AEOPs) stand out among the most promising technologies for treating refractory organic pollutants, including pharmaceutical compounds (Olvera-Vargas et al. 2021).

The presence of hydrogen peroxide promotes the production of the hydroxyl radical $(* \mathrm{OH})$ and, therefore, the oxidation potential can be improved (Sun et al. 2017; Bashir et al. 2018). Hydroxyl radicals are powerful secondary oxidizing agents, they are not selective, reacting quickly with organic compounds by means of hydroxylation with the addition of a hydroxyl group to an unsaturated bond or dehydrogenation, through the loss of a hydrogen atom, following a mechanism with radical until the conclusion of its mineralization, through the transformation of initial pollutants into carbon dioxide, water and inorganic ions (Boye et al. 2003; Asghar et al. 2015; Bashir et al. 2018).

Thus, the best conditions are sought to improve the efficiency of the peroxidation electrocoagulation process in the removal of contaminants of pharmaceutical origin, without the need to use large amounts of energy, and thus optimizing the current density, the concentration of $\mathrm{H}_{2} \mathrm{O}_{2}$ and the reaction time in the process. About this perspective, the objective of this work was to evaluate the application of EC associated with

\section{2. Materials and Methods}




\subsection{Synthetic effluent containing Ibuprofen}

Synthetic effluents were prepared containing Ibuprofen diluted in deionized water, in varying concentrations, according to the experimental planning matrix. Reagents with a pharmaceutical standard acquired in a handling pharmacy were used to prepare synthetic effluents. In preparing the solutions, it was necessary to add $5 \mathrm{~mL}$ of methanol in order to improve the dilution of the contaminant. In this study, analytical standards were used for HPLC analysis (Sigma Brand) to build the standard curve for quantification.

\subsection{Experimental module}

As electrodes for the electrocoagulation system, iron scrap was used, supplied by the Cercena Foundry Industry, located in the city of Erechim - RS, Brazil. The electrodes used had the dimensions of 12 $\mathrm{cm} \times 9 \mathrm{~cm} \times 3 \mathrm{~mm}$. In the ECP process, an electrochemical reactor on a laboratory scale made of glass was used, with dimensions $15 \mathrm{~cm}$ x $30 \mathrm{~cm}$, and a capacity for a volume of $3 \mathrm{~L}$ ( $2 \mathrm{~L}$ of synthetic effluent was used for each treatment (Fig. 2). The density of the electric current applied to the treatments was based on the literature, varying from 1 to $5 \mathrm{~A}$, the distance between the electrodes being fixed at $3 \mathrm{~cm}$. For a better conductivity in the synthetic effluent, $2 \mathrm{gL}^{-1}$ of NaCl was added to each treatment, and this value was obtained in preliminary tests as the most suitable for the system under study and then fixed for all tests. All tests were performed at room temperature $\left(20-25^{\circ} \mathrm{C}\right)$ under agitation of $100 \mathrm{rpm}$. The $\mathrm{pH}$ of the effluent remained with the natural value of the solution, close to neutral (6.5 - 7.5). It is worth mentioning that preliminary tests were performed without the addition of $\mathrm{H}_{2} \mathrm{O}_{2}$, where there was no significant removal of the drugs.

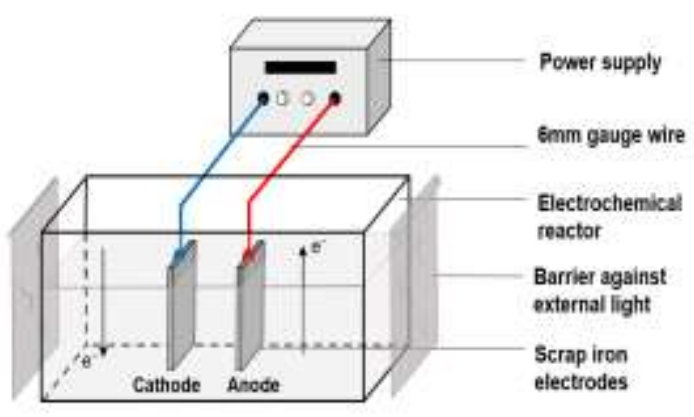

(a)

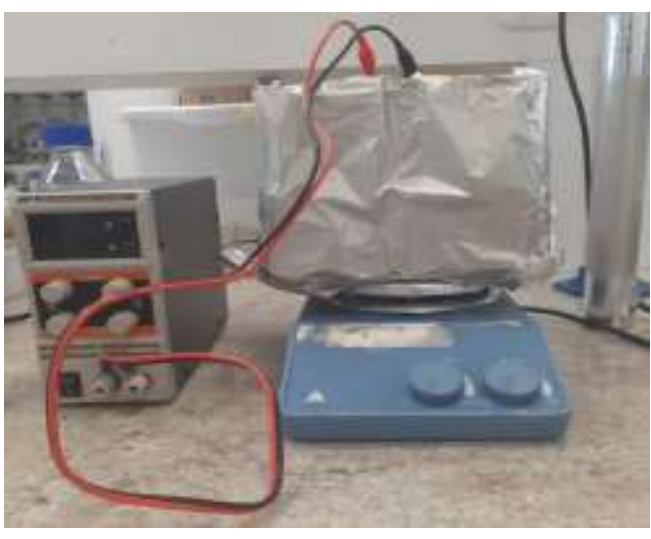

(b)

Fig. 2 Representative diagram of the electrocoagulation system (a) and real image of the system (b)

\subsection{Experimental procedure}

For the experimental design, the Central Rotational Composite Design (CCRD) was used (Rodrigues and Iemma 2009). Four independent variables were worked on: electric current, treatment time, Ibuprofen concentration and hydrogen peroxide concentration. A complete factorial design $2^{4}$ was carried out, including 8 axial points and 4 repetitions in the central points, totaling 28 tests. The efficiency of EC was based on the percentage of drug removal. Table 1 shows the coded values of the independent variables. It is noteworthy that the values of the independent variables were defined from preliminary tests with the effluent. Table 2 shows the matrix of the experimental design. The influence of the independent parameters was determined from the efficiency of removing the response or dependent parameter. From the empirical models obtained 
173 with the CCRD, the condition of optimization of the treatment process is obtained, in which the maximization

174 of efficiency in the removal of response variable is sought.

175 Table 1 Levels studied for the independent variables of the experimental design matrix

\begin{tabular}{lccccc}
\hline \multirow{2}{*}{ Independent variables } & \multicolumn{5}{c}{ Levels } \\
\cline { 2 - 6 } & -2 & -1 & 0 & 1 & 2 \\
\hline Ibuprofen concentration $\left(\mathrm{mg}^{-1} \mathrm{~L}^{-1}\right)$ & 5 & 10 & 15 & 20 & 25 \\
\hline $\mathrm{H}_{2} \mathrm{O}_{2}$ concentration $\left(\mathrm{mg}^{-1}\right)$ & 150 & 200 & 250 & 300 & 350 \\
\hline Current $(\mathrm{A})$ & 1 & 2 & 3 & 4 & 5 \\
\hline Time $(\mathrm{min})$ & 30 & 60 & 90 & 120 & 150 \\
\hline
\end{tabular}

176 Table 2 Experimental design matrix

\begin{tabular}{|c|c|c|c|c|c|c|c|c|}
\hline \multirow{3}{*}{$\begin{aligned} & \text { Test } \\
& 1\end{aligned}$} & \multirow{2}{*}{\multicolumn{4}{|c|}{ Coded variables }} & \multicolumn{4}{|c|}{ Independent variables } \\
\hline & & & & & \multirow{2}{*}{$\frac{\mathrm{IC}\left(\mathrm{mg} \cdot \mathrm{L}^{-1}\right)}{10}$} & \multirow{2}{*}{$\frac{\mathrm{H}_{2} \mathrm{O}_{2} \mathrm{C}\left(\mathrm{mg} \cdot \mathrm{L}^{-1}\right)}{200}$} & \multirow{2}{*}{$\frac{\mathrm{C}(\mathrm{A})}{2}$} & \multirow{2}{*}{$\frac{\mathrm{T}(\mathrm{min})}{60}$} \\
\hline & -1 & -1 & -1 & -1 & & & & \\
\hline 2 & -1 & -1 & -1 & 1 & 10 & 200 & 2 & 120 \\
\hline 3 & -1 & -1 & 1 & -1 & 10 & 200 & 4 & 60 \\
\hline 4 & -1 & -1 & 1 & 1 & 10 & 200 & 4 & 120 \\
\hline 5 & -1 & 1 & -1 & -1 & 10 & 300 & 2 & 60 \\
\hline 6 & -1 & 1 & -1 & 1 & 10 & 300 & 2 & 120 \\
\hline 7 & -1 & 1 & 1 & -1 & 10 & 300 & 4 & 60 \\
\hline 8 & -1 & 1 & 1 & 1 & 10 & 300 & 4 & 120 \\
\hline 9 & 1 & -1 & -1 & -1 & 20 & 200 & 2 & 60 \\
\hline 10 & 1 & -1 & -1 & 1 & 20 & 200 & 2 & 120 \\
\hline 11 & 1 & -1 & 1 & -1 & 20 & 200 & 4 & 60 \\
\hline 12 & 1 & -1 & 1 & 1 & 20 & 200 & 4 & 120 \\
\hline 13 & 1 & 1 & -1 & -1 & 20 & 300 & 2 & 60 \\
\hline 14 & 1 & 1 & -1 & 1 & 20 & 300 & 2 & 120 \\
\hline 15 & 1 & 1 & 1 & -1 & 20 & 300 & 4 & 60 \\
\hline 16 & 1 & 1 & 1 & 1 & 20 & 300 & 4 & 120 \\
\hline 17 & -2 & 0 & 0 & 0 & 5 & 250 & 3 & 90 \\
\hline 18 & 2 & 0 & 0 & 0 & 25 & 250 & 3 & 90 \\
\hline 19 & 0 & -2 & 0 & 0 & 15 & 150 & 3 & 90 \\
\hline 20 & 0 & 2 & 0 & 0 & 15 & 350 & 3 & 90 \\
\hline 21 & 0 & 0 & -2 & 0 & 15 & 250 & 1 & 90 \\
\hline 22 & 0 & 0 & 2 & 0 & 15 & 250 & 5 & 90 \\
\hline 23 & 0 & 0 & 0 & -2 & 15 & 250 & 3 & 30 \\
\hline 24 & 0 & 0 & 0 & 2 & 15 & 250 & 3 & 150 \\
\hline
\end{tabular}




\begin{tabular}{lllllllll}
\hline 25 & 0 & 0 & 0 & 0 & 15 & 250 & 3 & 90 \\
\hline 26 & 0 & 0 & 0 & 0 & 15 & 250 & 3 & 90 \\
\hline 27 & 0 & 0 & 0 & 0 & 15 & 250 & 3 & 90 \\
\hline 28 & 0 & 0 & 0 & 0 & 15 & 250 & 3 & 90
\end{tabular}

Note: IC - Ibuprofen concentration; $\mathrm{H}_{2} \mathrm{O}_{2} \mathrm{C}-\mathrm{H}_{2} \mathrm{O}_{2}$ concentration; $\mathrm{C}$ - current; $\mathrm{T}$ - time

\subsection{Analytical determination of Ibuprofen}

The determination of the concentration of the drug Ibuprofen during the tests, was done by means of high performance liquid chromatography (HPLC). For this, a chromatograph of the Shimadzu brand, model LCMS-2020, was used, equipped with a C18 column, $5 \mu \mathrm{m}$ in diameter, $250 \mathrm{~mm}$ in length and $4.6 \mathrm{~mm}$ in internal diameter, and a SPD-M20A photodiode network detector. The analysis occurred by isocratic elution, with the mobile phase consisting of $80 \%$ methanol HPLC $\left(\geq 99.9 \%\right.$ ) and $20 \%$ ultrapure water (mili-Q ${ }^{\circledR}$ ), acidified with $0.1 \%$ formic acid, flow $0,8 \mathrm{~mL} \cdot \mathrm{min}^{-1}$, injection volume of $20 \mu \mathrm{L}$, analysis time of $20 \mathrm{~min}$ and oven temperature of $30^{\circ} \mathrm{C}$, with the same temperature for the column. The quantification of the compound was performed through analytical curves with solutions of the analytical standards for each compound.

To create the analytical curve, standard solutions were prepared with eight concentrations, in the range of 0.05 to $20 \mathrm{ppm}$. Before all injections in the chromatograph, the raw and treated effluent went through a filtration process, with a $0.45 \mu \mathrm{m}$ PTFE filter.

\subsection{Sludge analysis}

The analysis of the contaminants in the sludge was performed after the peroxidation electrocoagulation with the optimized variables. At the end of the process, excess liquid was removed, sludge was collected in Falcon tubes, totaling 23 samples. These samples were centrifuged for $10 \mathrm{~min}$ at $1500 \mathrm{rpm}$. The solid was deposited at the bottom of the tubes, facilitating the removal of the supernatant for disposal. The sludge was resuspended, using $10 \mathrm{~mL}$ of methanol in each tube, followed by stirring. Again the tubes were centrifuged, under the same conditions. The supernatant methanol was removed, filtered with a 0.45 PTFE filter, the final volume was combined, and the sample was then injected into the chromatograph. Equation 7 can be used to check the concentration of total contaminants that has been removed.

$$
\left[C_{T R}\right]=\left[C_{I}\right]-\left(\left[C_{F L}\right]+\left[C_{L}\right]\right)
$$

$202\left[\mathrm{C}_{\mathrm{TR}}\right]=$ total contaminant concentration removed

$203\left[\mathrm{C}_{\mathrm{I}}\right]=$ initial contaminant concentration

$204\left[\mathrm{C}_{\mathrm{FL}}\right]=$ contaminant concentration in the liquid phase after ECP treatment

$205\left[\mathrm{C}_{\mathrm{L}}\right]=$ contaminant concentration in the sludge formed in the treatment

\subsection{Analysis of residual hydrogen peroxide}


To determine the total dissolved iron in the treated effluent, an analysis was performed by ICP-MS

213 (mass spectrometry with inductively coupled plasma), only in the sample under the optimized conditions.

\subsection{Statistical analysis}

215 For the statistical analysis of the results of the Central Composite Rotational Design (CCRD) matrix,

216 the Statistica ${ }^{\circledR} 7$ program was used to perform analysis of variance (ANOVA) and obtain the graphical 217 representation of the model, using a response surface graph and contour profile, which assists in determining 218 the optimal operating region for EC.

219 Since the model is valid for the response variables, the global desirability function, available in the 220 Statistica ${ }^{\circledR} 7$ program, is applied. This function is based on the precept that the quality of a process that has 221 many resources is completely unacceptable, if one of them is outside a desirable limit, aiming to find 222 conditions that can guarantee compliance with the criteria of all response variables and also provide the best 223 value in the response, with this value being the most desirable, converting the variables responses into a single 224 one, combining individual responses into a composite function, followed by their optimization (Candioti et 225 al. 2014).

\section{3. Results and discussion}

\subsection{Optimization of the ECP process}

With the objective of verifying the efficiency of the electrocoagulation treatment with the use of

230 scrap iron electrodes applied in the synthetic effluents containing Ibuprofen, the removal percentage was 231 calculated for each proposed test. The results obtained can be seen in Table 3, below.

232 Table 3 Removal of Ibuprofen by ECP process

\begin{tabular}{cccccc}
\hline & \multicolumn{4}{c}{ Independent variables } & $\%$ \\
\cline { 2 - 5 } Test & $\mathrm{IC}\left(\mathrm{mg} \cdot \mathrm{L}^{-1}\right)$ & $\mathrm{H}_{2} \mathrm{O}_{2} \mathrm{C}\left(\mathrm{mg} \cdot \mathrm{L}^{-1}\right)$ & $\mathrm{C}$ & $\mathrm{T}$ & $\begin{array}{c}\% \\
\text { Ibuprofen } \\
\text { removal }\end{array}$ \\
\hline 1 & 10 & 200 & 2 & 60 & 57,537 \\
\hline 2 & 10 & 200 & 2 & 120 & 88,339 \\
\hline 3 & 10 & 200 & 4 & 60 & 95,125 \\
\hline 4 & 10 & 200 & 4 & 120 & 89,551 \\
\hline 5 & 10 & 300 & 2 & 60 & 92,766 \\
\hline 6 & 10 & 300 & 2 & 120 & 96,146 \\
\hline 7 & 10 & 300 & 4 & 60 & 94,728 \\
\hline 8 & 10 & 300 & 4 & 120 & 90,991 \\
\hline 9 & 20 & 200 & 2 & 60 & 80,359 \\
\hline 10 & 20 & 200 & 2 & 120 & 71,794 \\
\hline
\end{tabular}




\begin{tabular}{|c|c|c|c|c|c|}
\hline 11 & 20 & 200 & 4 & 60 & 94,109 \\
\hline 12 & 20 & 200 & 4 & 120 & 84,505 \\
\hline 13 & 20 & 300 & 2 & 60 & 93,105 \\
\hline 14 & 20 & 300 & 2 & 120 & 95,681 \\
\hline 15 & 20 & 300 & 4 & 60 & 87,513 \\
\hline 16 & 20 & 300 & 4 & 120 & 95,589 \\
\hline 17 & 5 & 250 & 3 & 90 & 88,969 \\
\hline 18 & 25 & 250 & 3 & 90 & 94,831 \\
\hline 19 & 15 & 150 & 3 & 90 & 72,657 \\
\hline 20 & 15 & 350 & 3 & 90 & 97,702 \\
\hline 21 & 15 & 250 & 1 & 90 & 86,353 \\
\hline 22 & 15 & 250 & 5 & 90 & 99,882 \\
\hline 23 & 15 & 250 & 3 & 30 & 96,902 \\
\hline 24 & 15 & 250 & 3 & 150 & 96,641 \\
\hline 25 & 15 & 250 & 3 & 90 & 90,033 \\
\hline 26 & 15 & 250 & 3 & 90 & 96,004 \\
\hline 27 & 15 & 250 & 3 & 90 & 88,011 \\
\hline 28 & 15 & 250 & 3 & 90 & 94,538 \\
\hline
\end{tabular}

Note: IC - Ibuprofen concentration; $\mathrm{H}_{2} \mathrm{O}_{2} \mathrm{C}-\mathrm{H}_{2} \mathrm{O}_{2}$ concentration; $\mathrm{C}$ - current; T - time

According to the results of Table 3 , simultaneously analyzing all the tests, there were high removals of Ibuprofen, reaching more than 99\% removal. Khadir, Negarestani and Motamed (2020) applied electrocoagulation in water contaminated with Ibuprofen and, under the optimized conditions of $110 \mathrm{~min}, \mathrm{pH}$ $5,2 \mathrm{~A}$ of current and $3 \mathrm{~cm}$ of distance between the electrodes, the maximum removal was $63 \%$. It can be seen that there is a lot of variation in the removals, this may have happened because the electrodes are made of scrap iron and may differ from each other. It is worth mentioning that only in the tests with the lowest current and the shortest time (tests 21 and 23), the effluent, after treatment, presented residual hydrogen peroxide, with concentrations of $100 \mathrm{mg} \cdot \mathrm{L}^{-1}$.

The final $\mathrm{pH}$ of the treated effluent remained in the range close to neutral (6 - 7.5). According to de 244 Zaied et al. (2020), pH is a significant parameter in the performance of EC in the treatment of drug effluent, which removal efficiency reduces when the $\mathrm{pH}$ of the solution becomes alkaline or acid. Concluding that the removal efficiency with $\mathrm{pH}$ in the range of 5.74 to 7.48 is greater in comparison with the $\mathrm{pH}$ value of 7.48 to 8.26. In the study by Khadir, Negarestani and Motamedi (2020), where electrocoagulation was applied to remove Ibuprofen, they analyzed the removal efficiency with $\mathrm{pH}$ values of 2, 3, 5, 7 and 9 . The removal efficiency of $28.75 \%$ and $11.5 \%$ was reached at $\mathrm{pH} 2$ and 9, respectively. At $\mathrm{pHs} 3,5$ and 7 the removal efficiency was $46.55,63 \%$ and $35.75 \%$, respectively, with $\mathrm{pH} 5$ having the highest removal.

To validate the adjustment proposed by the results obtained, analysis of variance (ANOVA) was performed, based on the model provided for in the experimental design for the removal of Ibuprofen. The first stage of validation took place using the Pareto graph, shown in Figure 3, where it is possible to identify the 
254 parameters and interactions that significantly influence the dependent variables, with 95\% confidence, 255 represented by the red line. Linear variables are represented by $(\mathrm{L})$ and quadratic variables by $(\mathrm{Q})$, the positive 256 signs next to the bars indicate an increase in the removal of the parameters and the negative signs reduce the 257 parameters.

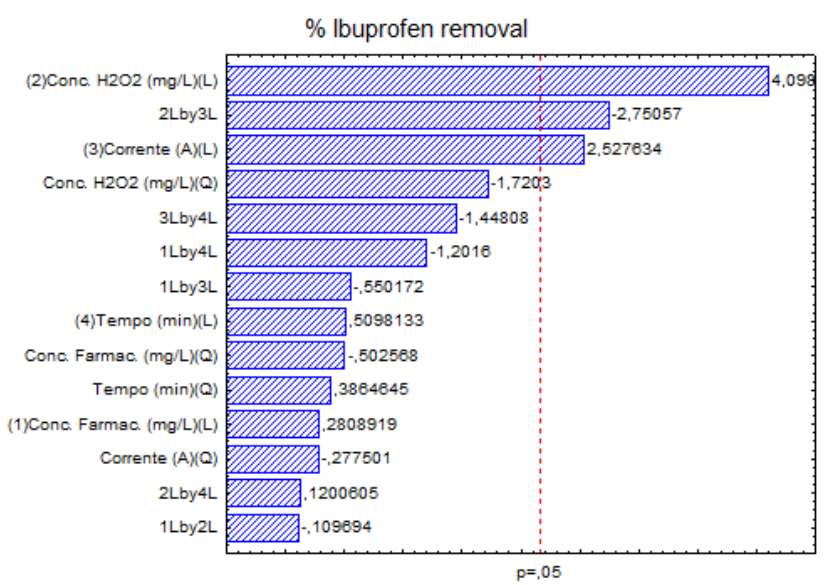

Standardized Effect Estimate (Absolute Value)

259 Fig. 3 Pareto Chart for Ibuprofen

According to the simultaneous analysis of the Pareto graphs, the $\mathrm{H}_{2} \mathrm{O}_{2}$ concentration and the current in linear terms proved to be efficient in the $95 \%$ confidence interval for removing Ibuprofen. The interaction between these two parameters in linear terms is also efficient in removing Ibuprofen. ANOVA results are shown in Table 4.

Table 4 Analysis of variance of the model foreseen for the removal of Ibuprofen from effluent treated by EC with iron electrode at a significance level of $95 \%(\mathrm{p}<0.05)$

\begin{tabular}{clccccc}
\hline Parameter & $\begin{array}{c}\text { Quadratic } \\
\text { model }\end{array}$ & $\begin{array}{c}\text { Sum of } \\
\text { squares }\end{array}$ & $\begin{array}{c}\text { Degrees of } \\
\text { freedom }\end{array}$ & Means & $\begin{array}{c}\mathrm{F}_{\text {calculated }} / \\
\mathrm{F}_{\text {tabulated }}\end{array}$ & p-value \\
\hline \multirow{2}{*}{$\begin{array}{c}\text { \% Ibuprofen } \\
\text { removal }\end{array}$} & Regression & 2347,165 & 14 & 167,655 & $3,692 /$ & 0,01204 \\
& Residuals & 590,28 & 13 & 45,406 & 2,554 & \\
& Total & 2937,445 & 27 & 213,061 & & \\
\hline
\end{tabular}

For the Ibuprofen removal variable, the p-value was statistically satisfactory at $95 \%$ confidence. It is

270 noteworthy that the value of $\mathrm{F}_{\text {calculated }}$ is greater than $\mathrm{F}_{\text {tabulated, }}$, which also proves that it is significant. In addition, 271 the regression is greater than the residuals for all variables, proving that the proposed statistical model is valid. 272 Subsequently, the response surface and contour profile graphs are shown (Fig. 4). The graphs express 273 the behavior of the percentage of removal of Ibuprofen, in function of the independent variables concentration 274 of hydrogen peroxide and applied current, the two variables that significantly influence in the removal of 275 Ibuprofen. 


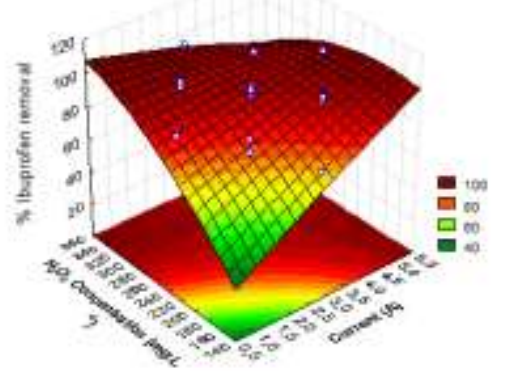

(a)

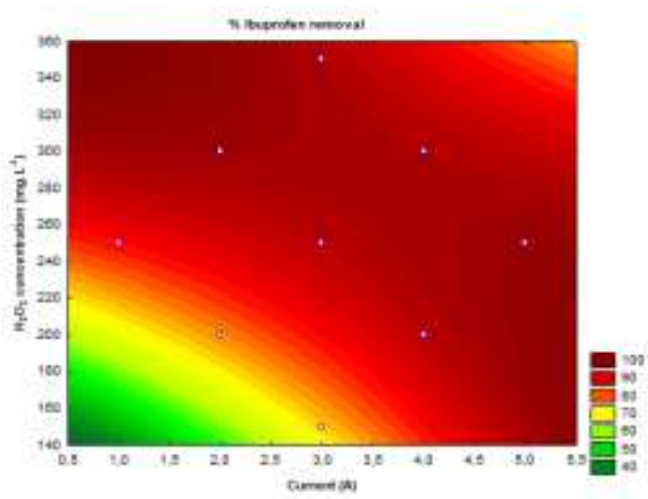

(b)

278 Fig. 4 (a) Response surface and (b) contour profile of Ibuprofen removal considering hydrogen peroxide 279 concentration and applied current

From Figure 4, it can be seen that when using hydrogen peroxide concentrations around $200 \mathrm{mg} . \mathrm{L}^{-1}$,

282 associated with an average applied current (4.5 - 5 A), influences an increase in efficiency of removing 283 Ibuprofen. Also, it can be seen that higher values of hydrogen peroxide are associated with greater removal 284 of Ibuprofen as well. According to the study by Khadir, Negarestani and Motamedi (2020), the greatest 285 removal of Ibuprofen by electrocoagulation was $54.75 \%$ using a current of 2 A, for 110 min. This trend can 286 be attributed to the phenomenon that with increasing current density, the rate of dissolution of the anode 287 increases, leading to greater removal.

\subsection{Global desirability}

290 As observed in the statistical analysis, the response variable for removing Ibuprofen was significant 291 at the $95 \%$ confidence level. Thus, it was decided to use the function Desirability, from the software 292 Statistica ${ }^{\circledR}$ 7, which allows the optimization of multiple response variables, to determine the optimized 293 operational values of the independent variables aiming at greater removal of the dependent variables. Figure 2945 shows the optimal work values. The overall desirability value varies from 0 to 1 , the closer it is to 1 , the 295 closer the response obtained to that intended. The overall function obtained was equal to 1, thus indicating an excellent response. 


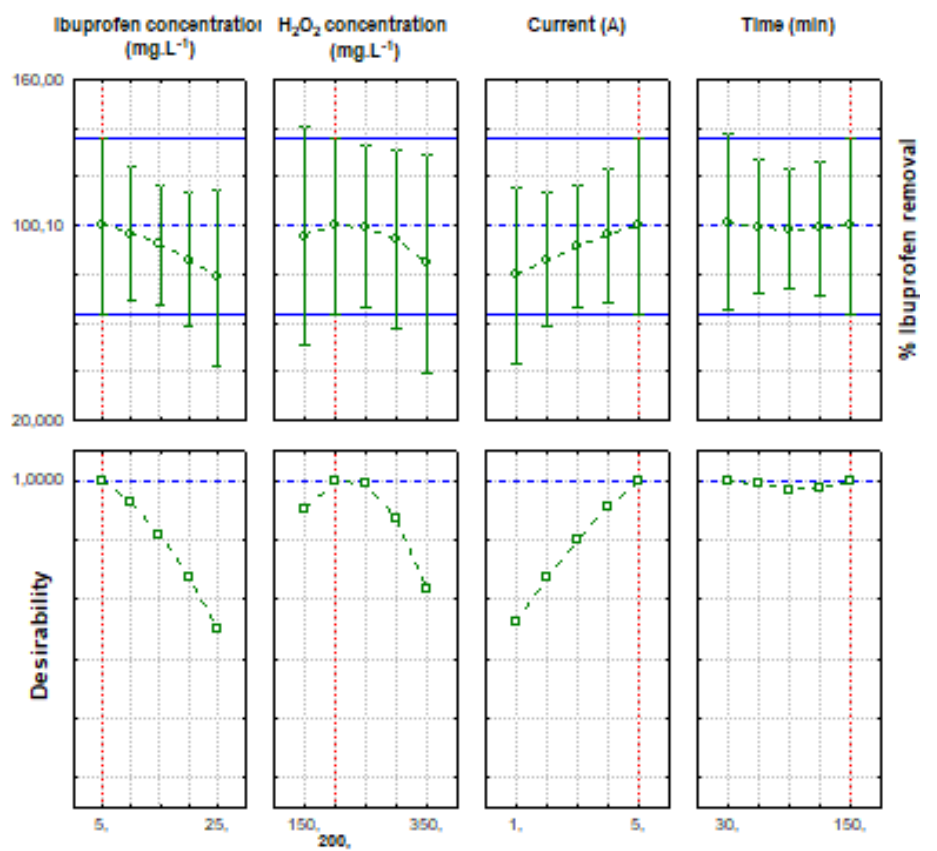

298 Fig. 5 Simultaneous optimization of dependent variables through the Global Desirability function

The red line in the graphs indicates the optimized values of the variables drug concentration, hydrogen peroxide concentration, current and treatment time at: $5 \mathrm{mg} \cdot \mathrm{L}^{-1}, 200 \mathrm{mg} \cdot \mathrm{L}^{-1}, 5 \mathrm{~A}$ and $150 \mathrm{~min}$, respectively, aiming at greater removal possible of Ibuprofen. From these conditions, $100 \%$ drug removal is expected to occur. Mission et al. (2011) obtained the greatest removal of Ibuprofen using a current of 21,4 V. Velasquez (2019) removed $87.61 \%$ of Ibuprofen using a current of $8 \mathrm{~A}$ and 20 minutes. Negarestani et al. (2020) obtained the greatest removal of Ibuprofen with the optimized values of $110 \mathrm{~min}$ and $2 \mathrm{~A}$ and drug concentration of $40 \mathrm{ppm}$. The treatment is enhanced with the addition of $\mathrm{H}_{2} \mathrm{O}_{2}$, allowing greater removal of the contaminant in a shorter time (Pereira et al. 2018).

\subsection{Validation of the proposed model}

Through the electrocoagulation test using the optimized condition obtained through the Global Desirability test, it is possible to validate the results obtained in Figure 5. A removal close to $100 \%$ was expected, however the actual removal obtained using the optimized conditions was 92, 91\%, still resulting in a concentration of $0.4 \mathrm{mg} . \mathrm{L}^{-1}$ for Ibuprofen. In their study, Yoosefian et al. (2017) applied electrocoagulation with iron electrodes to remove the antibiotic ciprofloxacin. With the variables initial concentration, $\mathrm{pH}$, current, time and distance between electrodes optimized, the expected removal was $99 \%$ and the experimental one was 100\%. Irdemenez et al. (2006) applied electrocoagulation to remove phosphate from effluents with aluminum electrodes. With the parameters optimized, the estimated and experimental phosphate removal from wastewater was $76 \%$ and $99 \%$, respectively. With another configuration, the actual removal was $93 \%$ and $99 \%$ predicted. The difference between the actual and the estimated value may be related to the fact that the electrodes used in this work are made of scrap iron material. 
residual Ibuprofen of $0.628 \mathrm{mg} . \mathrm{L}^{-1}$. Thus, it was possible to verify through Eq. 07 that there was a removal of

$32379.4 \%$ of the contaminant.

324 Some studies report the possibility of removing $95 \%$ of organic contaminants just by applying the

325 electrochemical process (Urtiaga et al. 2014), however, it must be emphasized that the characteristics of the

326 system, as well as the concentration of the contaminant and its structural peculiarities that will define the

327 efficiency of the process. It should be noted that the presence of Ibuprofen in the sludge, shows that the

328 physical-chemical processes can assist in the treatment of this type of contaminant, and if associated with

329 other methods, their efficiency can be enhanced.

\subsection{Total Iron Residual}

The result obtained for the total iron residual was $132.4 \mathrm{mg} . \mathrm{L}^{-1}$. The high concentration can be attributed mainly to the high current that was employed (Giordanni 2017). Ryan, McNamara and Mayer (2020) used electrocoagulation with iron electrodes to remove disinfection by-products in the water. The residual iron after the process was between 4.6 to $5.8 \mathrm{mg} \mathrm{Fe} . \mathrm{L}^{-1}$. Pereira and Brito (2018) obtained, at the end of the treatment process for the removal of laboratory effluents, the concentration of residual total soluble iron was $6.40 \mathrm{mg} . \mathrm{L}^{-1}$. In Figure 6, it is possible to see the difference between the synthetic effluent after the treatment, with a color change due to the presence of the sludge containing the iron, and after it is filtered with a 0.45 $\mu \mathrm{m}$ PTFE filter.

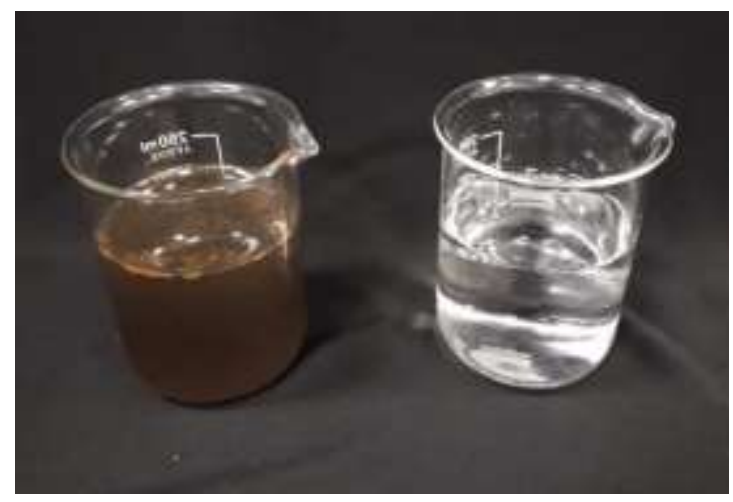

(a)

(b)

342 Fig. 6 (a) Synthetic effluent after electrocoagulation-peroxidation and (b) after filtration

The Brazilian Resolution of the National Environment Council No. 430, of May 13, 2011, presents conditions and standards for the discharge of effluents. It provides that the effluents from any polluting source can only be released directly into the receiving body if they have a dissolved iron value below $15 \mathrm{mg} . \mathrm{L}^{-1}$.

347 Although iron is not toxic, its presence in high concentrations can affect aquatic life, public supply and human

348 health. Therefore, secondary treatment is necessary for enable the effluent to be released into the receiving 349 water body.

\section{Conclusions}


Electrocoagulation using scrap iron electrodes proved to be an efficient treatment for the removal of

354 Ibuprofen from effluents, with an average removal of more than $90 \%$ and with no residual hydrogen peroxide in most of the tests. Analysis of variance showed that the model is valid with $95 \%$ confidence in removing Ibuprofen. The analysis of the global desirability function and the response surface, made it possible to determine the optimized values of the independent variables, and the actual removal for Ibuprofen was $92 \%$ in the liquid phase, showing that the treatment is efficient. Still, the importance of using industrial waste in the manufacture of the electrodes used in this study is emphasized, adding value to scrap iron.

It is suggested a post-treatment step to remove dissolved iron that is in disagreement with the limit stipulated in environmental legislation and to determine the intermediate compounds formed from this process, in order to enable the verification of the mineralization capacity of this system.

\section{References}

Aquino Neto S, Magri TC, Silva GM, Andrade AR (2011) Treatment of waste dye by electroflocculation: an experiment for undergraduate in chemistry. Química Nova 3(8):1468-1471. https://doi.org/10.1590/S0100-40422011000800030

Aranami K, Readman JW (2007) Photolytic degradation of triclosan in freshwater and seawater.

Arrais PSD, Fernandes MEP, Pizzol TSD, Ramos LR, Mengue SS, Luiza VL, Tavares NUL, Farias MR, Oliveira MA, Bertoldi AD (2016) Prevalência da automedicação no Brasil e fatores associados. Revista Saúde Pública 50. https://doi.org/10.1590/s1518-8787.2016050006117

Asghar A, Raman AAA, Daud WMAW (2015) Advanced oxidation processes for in-situ production of hydrogen peroxide/hydroxyl radical for textile wastewater treatment: a review. J. Clean. Prod. 87. https://doi.org/10.1016/j.jclepro.2014.09.010

Bashir MJK, Lim JH, Amr SSA, Wong LP, Sim YL (2018) Pos treatment of Palm Oil Mill effluent using electro-coagulation-peroxidation (ECP) technique. Journal of Cleaner Production. https://doi.org/10.1016/j.jclepro.2018.10.073

Behling L, Pavão DB, Alves AAA, Santos BLB, Tones ARM (2018) Electroflocculation applied in the treatment of milk effluent: experimental design and optimization of multiple responses. International Symposium on Environmental Quality. https://researchgate.net/publication/330501197 (in Portuguese)

Boye B, Dieng MM, Brillas E (2003) Anodic oxidation, electro-Fenton and photoelectro- Fenton treatments of 2, 4, 5-trichlorophenoxyacetic acid. J. Electroanalyt. Chem 557. https://doi.org/10.1016/S0022$\underline{0728(03) 00366-8}$

Conama (2011) CONAMA Resolution no 430/2011. Brasília. (in Portuguese) http://www2.mma.gov.br/port/conama/legiabre.cfm?codlegi=646. Accessed 15 mar 2021 optimization. Using the desirability function in analytical methods development. Talanta 124:123-138. https://doi.org/10.1016/j.talanta.2014.01.034 
Carvalho DL, Souza MAC, Zempulski DA (2015) Use of the electroflocculation method for the treatment of industrial effluents. National Journal of City Management 3(14):14-28. http://dx.doi.org/10.17271/231884723142015934 (in Portuguese)

Chen G (2004) Electrochemical technologies in wastewater treatment. Separation and Purification Technology 38:11-41. https://doi.org/10.1016/j.seppur.2003.10.006

Cometti MF, Nascimento IL, Mattedi EVO, Paiva WV, Rocha SMS (2014) Electroflocculation with different Al electrodes. In: Brazilian Chemical Engineering Congress. (in Portuguese)

Cordeiro RB, Alexandre JIS, Silva JPF, Sales DCS, Cavalcanti LAP (2015) Purification and reuse of wastewater from biodiesel production through electroflocculation. Brazilian Journal of Environmental Management and Sustainability 2:51-58. https://biblat.unam.mx/pt/revista/revista-brasileira-de-gestaoambiental-e-sustentabilidade/articulo/purificacao-e-reutilizacao-de-aguas-residuarias-da-producao-debiodiesel-por-meio-da-eletrofloculacao (in Portuguese)

Deghles A, Kurt U (2016) Treatment of tannery wastewater by a hybrid electrocoagulation/ electrodialysis process. Chemical Engineering and Processing: Process Intensification 104. https://doi.org/10.1016/j.cep.2016.02.009

Ebele AJ, Abdallah MA, Harrad S (2016) Pharmaceuticals and personal care products (PPCPs) in the freshwater aquatic environment. Emerging Contaminants 1-16. https://doi.org/10.1016/j.emcon.2016.12.004

Eryuruk K, Um UT, Ogutveren UB (2018) Electrochemical treatment of wastewaters from poultry slaughtering and processing by using iron electrodes. Journal of Cleaner Production 172:1089-1095. https://doi.org/10.1016/j.jclepro.2017.10.254

Gabriel HS (2017) Electrocoagulation as a pretreatment of effluents from the chemical industry. Dissertation, Federal University of Rio de Janeiro. (in Portuguese)

Giordanni PR (2017) Use of iron sacrifice electrodes in the electroflocculation of the effluent from the cosmetic industry: evaluation of treatment efficiency. Dissertation, Federal University of Fronteira Sul. (in Portuguese)

Írdemez S, Yildiz YS, Tosunoğlu V (2006) Optimization of phosphate removal from wastewater by electrocoagulation with aluminum plate electrodes. Separation and Purification Technology 52:394-401. https://doi.org/10.1016/j.seppur.2006.05.020

Khadir A, Negarestani M, Motamedi M (2020) Optimization of an electrocoagulation unit for purification of ibuprofen from drinking water: Effect of conditions and linear/non-linear isotherm study. Separation Science And Technology 56:1431-1449. https://doi.org/10.1080/01496395.2020.1770795

Khemila B, Merzouk B, Chouder A, Zidelkhir R, Leclerc JP, Lapicque F (2018) Removal of a textile dye using photovoltaic electrocoagulation. Sustainable Chemistry and Pharmacy 7:27-35. https://doi.org/10.1016/j.scp.2017.11.004

Machado KC, Grassi MT, Vidal C, Pescara IC, Jardim WF, Fernandes AN, Sodré FF, Almeida FV, Santana JS, Canela MC, Nunes CRO, Bichinho KM, Severo FJR (2016) A preliminary nationwide survey of the 
presence of emerging contaminants in drinking and source waters in Brazil. Science of the Total Environment 572:138-146. https://doi.org/10.1016/j.scitotenv.2016.07.210

Mission EG, Gaspillo PD, Belo LP, Cruz GPT (2011) effect of electrode assembly on the performance of a compact electrocoagulation reactor system applied to pharmaceutical residue ibuprofen. Regional Conference on Chemical Engineering, Philippines. https://www.researchgate.net/publication/257947326

Mollah MYA, Morkovsky P, Gomes JAG, Kesmez M, Parga J, Cocke DL (2004) Fundamentals, present and future perspectives of electrocoagulation. Journal of hazardous Materials 114:199-210. https://doi.org/10.1016/j.jhazmat.2004.08.009

Nagarestani M, Motamedi M, Kashtiarray A, Khadir A, Sillanpää M (2020) Simultaneous removal of acetaminophen and ibuprofen from underground water by an electrocoagulation unit: Operational parameters and kinetics. Groundwater for Sustainable Development 11. https://dx.doi.org/10.1016/j.gsd.2020.100474

Naidu R, Espana VAA, Liu Y, Jit J (2016) Emerging contaminants in the environment: Risk-based analysis for better management. Chemosphere 154:350-357. https://doi.org/10.1016/j.chemosphere.2016.03.068

Olvera-Vargas H, Gore-Datar N, Garcia Rodriguez O, Mutnuri S, Lefebvre O (2021) Electro-Fenton treatment of real pharmaceutical wastewater paired with a BDD anode: Reaction mechanisms and respective contribution of homogeneous and heterogeneous-OH. Chemical Engineering Journal 404. https://doi.org/10.1016/j.cej.2020.126524

Pavão DB, Alves AAA, Behling L, Tones ARM (2018) Electroflocculation with the use of aluminum electrode in the treatment of the tannery effluent: experimental optimization and response surface. International Symposium on Environmental Quality https://www.researchgate.net/publication/330501421 (in Portuguese)

Pereira CAM, Brito NN (2018) Integration of treatment technologies with Fenton reagent for laboratory effluent remediation. Revista Ambient. Água 13. https://doi.org/10.4136/ambi-agua.2243

Pereira RS (2018) Evaluation of slurry treatment by electrocoagulation process associated with hydrogen peroxide as a catalyst by the fenton process. In: International Symposium on Environmental Quality. https://anais.unilasalle.edu.br/index.php/sefic2017/article/view/839 (in Portuguese)

Rodrigues MI, Iemma AR (2009) Experiment planning and process optimization. Casa do Espirito Amigo Fraternidade Fé e Amor, São Paulo. (in Portuguese)

Ryan DR, McNamara PJ, Mayer BK (2020) Iron-electrocoagulation as a disinfection byproduct control strategy for drinking water treatment. Environmental Science: Water Research \& Technology 6. https://doi.org/10.1039/D0EW00106F

Santos JL, Aparicio I, Callejón M, Alonso E (2009) Occurrence of pharmaceutically active compounds during 1-year period in wastewaters from four wastewater treatment plants in Seville (Spain). Journal of Hazarduos Materials 164. https://doi.org/10.1016/j.jhazmat.2008.09.073 pharmaceuticals in wastewater from households, livestock farms, hospitals and pharmaceutical manufactures. Chemosphere 82. https://doi.org/10.1016/j.chemosphere.2010.10.026 
Sun Z, Liu Z, Hu X (2017) Electro-coagulation with Periodically Reversing-H2O2 Treating Chloramphenicol Pharmaceutical Wastewater. Int. Conference on Energy, Power and Environmental Engineering. https://doi.org/10.12783/dteees/icepe2017/11884

Tones ARM (2015) Study of the application of the electroflocculation technique in the removal of color in mixtures of textile dyes. Dissertation, Federal Technological University of Paraná. (in Portuguese)

470 Torres NH, Américo JHP, Ferreira LFR, Nazato C, Maranho LA, Vilca FZ, Tornisielo VL (2012) Drugs in 471 the environment - review. Revista de estudos ambientais 14(4):67-75.

472 https://www.academia.edu/26631018 (in Portuguese)

473 Urtiaga A, Fernandez-Castro P, Gómez P, Ortiz I (2014) Remediation of wastewaters containing

474 tetrahydrofuran. Study of the electrochemical mineralization on BDD electrodes. Chemical Engineering

475 Journal 239:341-350. https://doi.org/10.1016/j.cej.2013.11.028

476 Velasquez B, Tafur KKM, Melina M (2019) Reduction of Ibuprofen concentration in water by

477 electrocoagulation, at the laboratory level. César Vallejo University.

478 https://hdl.handle.net/20.500.12692/36654 (in Spanish)

479 Yoosefian M, Ahmadzadeh S, Aghasi M, Dolatabadi M (2017) Optimization of electrocoagulation process

480 for efficient removal of ciprofloxacin antibiotic using iron electrode; kinetic and isotherm studies of

481 adsorption. Journal of Molecular Liquids 225:544-553. https://doi.org/10.1016/j.molliq.2016.11.093

482 Zaied BK, Rashid M, Nasrullah M, Zularisam AW, Pant D, Singh L (2020) A comprehensive review on

483 contaminants removal from pharmaceutical wastewater by electrocoagulation process. Science of the

484 Total Environment 726. https://doi.org/10.1016/j.scitotenv.2020.138095

485 Zhao J, Xin M, Zhang J, Sun Y, Luo S, Wang H, Wang Y, Bi X (2019) Diclofenac inhibited the biological 486 phosphorus removal: Performance and mechanism. Chemosphere 243.

487 https://doi.org/10.1016/j.chemosphere.2019.125380 